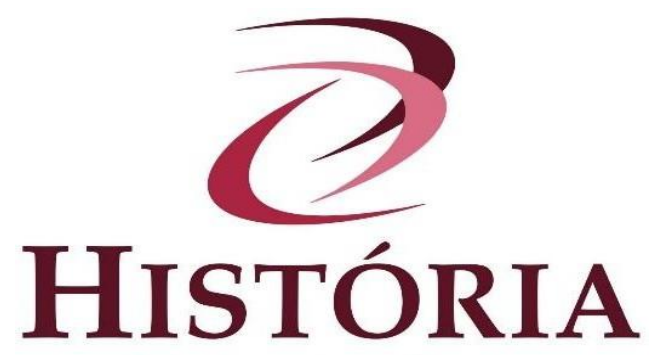

\title{
Subdesenvolvimento e desenvolvimento no contexto da Cepal: o embate entre dependência e interdependência na América Latina
}

\author{
Underdevelopment and development in the context of Cepal: the clash between \\ dependence and interdependence in Latin America
}

\author{
Subdesarrollo y desarrollo en el contexto Cepal: la lucha entre dependencia e \\ interdependencia en América Latina
}

Jadir Peçanha Rostoldo*

\begin{abstract}
Resumo: O objetivo deste artigo é expor, a partir de uma revisão bibliográfica, o debate econômico sobre as teorias do subdesenvolvimento e da dependência, tendo como referência o pensamento econômico desenvolvido pela Comissão Econômica para a América Latina (Cepal). A partir das concepções da Cepal apresenta as conexões do subdesenvolvimento e da dependência com a formação econômica dos países latino-americanos. Discute o embate envolvendo a dialética da dependência e a interdependência entre os sistemas econômicos. Ratifica a importância da Cepal para o entendimento do processo econômico na América Latina.
\end{abstract}

Palavras-chave: América Latina. Dependência. Subdesenvolvimento.

\begin{abstract}
The aim of this article is to expose, based on a bibliographic review, the economic debate on the theories of underdevelopment and dependency, having as reference the economic thinking developed by the Economic Commission for Latin America (CEPAL). Based on CEPAL's conceptions, it presents the connections of underdevelopment and dependence with the economic formation of Latin American countries. It discusses the clash involving the dialectic of dependency and the interdependence between economic systems. It confirms the importance of CEPAL for the understanding of the economic process in Latin America.
\end{abstract}

Keywords: Latin America. Dependency. Underdevelopment.

Resumen: El objetivo de este artículo es exponer, a partir de una revisión bibliográfica, el debate económico sobre las teorías del subdesarrollo y la dependencia, teniendo como referencia el pensamiento económico desarrollado por la Comisión Económica para América Latina (CEPAL). A partir de las concepciones de la CEPAL, presenta las conexiones del subdesarrollo y la dependencia con la formación económica de los países latinoamericanos. Discute el choque que involucra la dialéctica de la dependencia y la interdependencia entre sistemas económicos. Confirma la importancia de la CEPAL para la comprensión del proceso económico en América Latina.

Palabras clave: América Latina. Dependencia. Subdesarrollo. 


\section{Introdução}

Quando se propõe uma discussão sobre a situação econômica da América Latina as questões do subdesenvolvimento e da dependência acabam sendo apontadas. Em diversas situações e análises os países latino-americanos são classificados de dependentes e subdesenvolvidos. Dentro dessa lógica, a abordagem proposta neste artigo é expor o debate econômico sobre essas teorias, tendo como referência o pensamento econômico desenvolvido pela Comissão Econômica para a América Latina (Cepal).

A importância da Cepal, em relação às discussões acerca da deterioração dos termos de troca, compreende um dos temas fundamentais para se entender o processo de desenvolvimento econômico e social da região. Os movimentos e as estruturas que caracterizam essa relação são um dos caminhos para identificar as transformações no território latino-americano, que se refletiram profundamente em sua história econômica, política e social. Os temas do subdesenvolvimento e do desenvolvimento sempre estiveram presentes no pensamento dessa organização, que a partir da década de 1950 se tornou uma referência para os estudos nessa região das Américas. Na primeira parte do artigo, o papel da Cepal na formação do pensamento econômico latino-americano será discutido no sentido de indicar sua importância nesse processo.

Nesse contexto, a construção da visão de dependência e subdesenvolvimento será debatida tendo como base o aporte teórico de importantes pesquisadores que se ocuparam por desvendar essa relação. No tópico final, o embate entre dependência e interdependência, no arcabouço do subdesenvolvimento, será apresentado com foco no entendimento das transformações na América Latina. O objetivo é estabelecer a relação entre os princípios da Cepal, que serviram como referência para discussão e formação do pensamento econômico latino-americano, com as diversas teorias e propostas que cercam o processo de desenvolvimento dos países sob sua influência.

\section{A Cepal e a deterioração dos termos de troca}

A Comissão Econômica para a América Latina (Cepal) foi constituída em 1948, por decisão da Assembleia Geral das Nações Unidas. A criação ocorreu no contexto das queixas latinoamericanas de exclusão com relação ao Plano Marshall, que apoiou a recuperação da Europa e do Japão após a segunda guerra mundial, e da falta de acesso aos dólares escassos, que dificultava a reposição dos desgastados aparelhos produtivos da região. A percepção generalizada à época 
parecia ser a de que a nova organização estaria fadada a tornar-se mais uma entre as inúmeras agências internacionais inexpressivas e burocratizadas já existentes (BARBOSA, 2012).

O economista e ex-gerente do Banco Central Argentino, Raúl Prebisch, tornou-se secretário executivo da Cepal em 1950 e mudou o rumo da organização. Produziu estudos que continham os elementos que passariam a figurar como a grande referência ideológica e analítica para os desenvolvimentistas latino-americanos. Primeiro, argumentou que a industrialização espontânea em curso tinha significado especial na história da humanidade, porque representava a possibilidade de captação pela vasta região subdesenvolvida latino-americana dos frutos do progresso técnico mundial, até então essencialmente confinados aos países industrializados. Segundo, apresentou os elementos da matriz analítica da qual arranca o pensamento cepalino. Neles encontram-se tanto a análise da inserção internacional das economias periféricas e da vulnerabilidade externa decorrente, como a análise das condições problemáticas e das tendências perversas com que se processa internamente o crescimento na periferia latino-americana. Por último, realiza uma primeira incursão na temática da intervenção estatal, que surge fortalecida pelo argumento da natureza problemática da industrialização nas condições estruturais periféricas, que o mercado não teria como resolver espontaneamente (BIELSCHOWSKY, 2000).

A agenda de reflexão e investigação inauguradas por Prebisch (1949) compunha-se essencialmente do diagnóstico da profunda transição que se observava nas economias subdesenvolvidas latino-americanas, do modo de crescimento primário-exportador, para fora, ao modelo urbano-industrial, para dentro. $\mathrm{O}$ enfoque histórico foi poderosamente instrumentalizado pela teoria estruturalista do subdesenvolvimento periférico de Prebisch. A perspectiva estruturalista se instalou no centro das análises como consequência direta do objeto de reflexão a que a instituição se propunha. Tratava-se de examinar o modo próprio como se dava a transição para dentro nos países da América Latina, transição que se entendia repousar sobre a condição de que o processo produtivo se movia sobre uma estrutura econômica e institucional subdesenvolvida, herdada do período exportador.

$\mathrm{Na}$ análise econômica cepalina o estruturalismo é essencialmente um enfoque orientado pela busca de relações diacrônicas, históricas e comparativas, que se presta mais ao método indutivo do que a uma heurística positiva. Daí resultou fatores essenciais para a construção teórica da análise histórica comparativa da Cepal: as estruturas subdesenvolvidas da periferia latinoamericana condicionam, mais que determinam, comportamentos específicos de trajetórias a priori 
desconhecidas. Por essa razão, merecem e exigem estudos e análises nos quais a teoria econômica com selo da universalidade só pode ser empregada com qualificações, de maneira a incorporar essas especificidades históricas e regionais. Em outras palavras, o enfoque histórico-estruturalista cepalino abriga um método de produção de conhecimento profundamente atento para o comportamento dos agentes sociais e da trajetória das instituições, que tem maior proximidade a um movimento indutivo do que os enfoques abstrato-dedutivos tradicionais (VIEIRA; CARVALHO, 2004).

A riqueza do método cepalino reside, pois, numa fértil interação entre o método indutivo e a abstração teórica formulada originalmente por Prebisch. A oposição entre periferia e centro, que desempenhou duplo papel analítico, ilustra esse ponto. Primeiro, serviu para o argumento de que a referida estrutura determinou um padrão específico de inserção na economia mundial, como periferia da mesma, produtor de bens e serviços com demanda internacional pouco dinâmica, importadora de bens e serviços com demanda doméstica em rápida expansão, e absorvedora de padrões de consumo e tecnologias adequadas ao centro, mas frequentemente inadequadas a disponibilidade de recursos e ao nível de renda da periferia. Segundo, prestou-se a ideia de que a estrutura socioeconômica periférica determina um modo próprio de industrializar, introduzir progresso técnico e crescer, e um modo próprio de absorver a força de trabalho e distinguir a renda. Ou seja, em suas características centrais, o processo de crescimento, emprego e distribuição da renda na periferia seria distinto do que ocorre nos países centrais. As diferenças devem ser encontradas no fato de que as economias periféricas possuem uma estrutura pouco diversificada e tecnologicamente heterogênea, que contrasta com o quadro encontrado na situação dos países centrais. Nesse o aparelho produtivo é diversificado, tem produtividade homogênea ao longo de toda a sua extensão, e tem mecanismos de criação e difusão tecnológica e de transmissão social de seus frutos inexistentes na periferia (BIELSCHOWSKY, 2000).

Não se tratava de comparar o subdesenvolvimento periférico com a história pretérita das economias centrais. Para os autores cepalinos, o desenvolvimento nas condições de periferia latinoamericana não seria uma etapa de um processo universal do desenvolvimento, mas um processo inédito, cujos desdobramentos históricos seriam singulares a especificidade de suas experiências, cabendo esperarem-se sequenciais e resultados distintos aos que ocorreram no desenvolvimento centrico. 
A análise cepalina tem como um dos seus instrumentos básicos a dialética do contraste entre o modo com que o crescimento, o progresso técnico e o comércio internacional ocorrem nas estruturas econômicas e sociais dos países periféricos e o modo como ocorrem nos países centrais. O contraste presta-se, no caso do exame do comércio internacional, para destacar as interdependências entre o comportamento do centro e o da periferia e os problemas que geram para os últimos. A violenta contração da capacidade para importar nos anos 1930 e suas repercussões sobre as economias latino-americanas constituíram a referência histórica principal para a elaboração, por parte de Prebisch, da distinção entre o modo de funcionamento das economias dos países industrializados e aquele encontrado em economias especializadas em bens primários.

$\mathrm{Na}$ Cepal o argumento ganhou contundência porque foi acompanhado da tese da tendência a deterioração dos termos de troca, que afrontava o postulado liberal das virtudes do comércio internacional livre. Ao contrario do que prometia a teoria das vantagens comparativas, durante o século XX a maior lentidão no progresso técnico dos produtos primários em relação aos industriais não estava motivando o encarecimento dos primeiros em relação aos últimos. A tese teve duas versões, ambas estruturalistas, e ambas centradas na ideia das vantagens comparativas dinâmicas da produção industrial, ou das desvantagens comparativas dinâmicas da especialização em bens primários (MARÇAL, 2006).

Na primeira versão a tese vinculava-se aos ciclos e a forma como a estrutura de produção e emprego subdesenvolvida impedia a periferia de reter os frutos do seu progresso técnico, a diferença do que ocorria no centro. Ai, sindicatos organizados e uma estrutura produtiva concentrada logravam impedir a queda nominal de preços compensando, dessa forma, os ganhos que a periferia obtinha no auge cíclico com os bens primários. Na segunda versão, contemplava a tendência potencial a deterioração, devida ao excesso de mão-de-obra na agricultura subdesenvolvida da periferia, não transferível aos países centrais, fechados a imigração, cujo eventual emprego em atividades exportadoras resultaria em expansão da oferta que deprimiria os preços internacionais, resultando em menos valor apesar do maior volume de produção. Adolfo Gurrieri analisando a economia política de Prebisch, sobre esse tema, reconhece que

[...] los centros son capaces de impulsar incrementos de productividad muy superiores a los de la periferia por su potencial científico-técnico y de acumulación de capital; se especializan en la producción de aquellos bienes que tienen una demanda creciente en relación al ingreso; controlan el dinamismo económico por la posición de liderazgo que ocupa la demanda de bienes industriales en relación a la de los primarios; poseen una estructura económico-social que favorece la capacidad de retención de sus agentes económicos en relación a los de la periferia (homogeneidad y diversificación 
productivas y mayor organización empresarial y sindical); y, finalmente, aplican medidas directas para proteger su nivel de ingreso de la competencia externa. (GURRIERI, 1981, p. 21).

A lógica da argumentação cepalina era que enquanto ocorresse o processo de industrialização, não relaxaria a vulnerabilidade externa, porque por muito tempo manter-se-ia na periferia latino-americana a condição de exportadora de produtos primários, de demanda inelástica nos países cêntricos, e de importadora de produtos industriais, de alta elasticidade da demanda na periferia. Assinalava que, enquanto não fosse concluído, o processo de industrialização enfrentaria permanentemente uma tendência ao desequilíbrio estrutural do balanço de pagamentos, já que o processo substitutivo aliviava as importações por um lado, mas impunha novas exigências, derivadas tanto da nova estrutura produtiva que criava, como do crescimento da renda que gerava. Por essa razão, apenas alternava-se a composição das importações, renovando-se continuamente o problema da insuficiência de divisas (KANNEBLEY; GREMAUD; RENNÓ, 2001).

Dessa forma, os argumentos teóricos básicos, de Prebisch (1949), sobre sua tese da deterioração dos termos de troca podem ser assim apresentados: a tese de Prebisch relaciona-se, exatamente, ao fato de que deveríamos esperar uma deterioração secular dos termos de troca entre produtos primários e produtos manufaturados em virtude da interação de vários fatores. Em primeiro lugar, se existe, por um lado, uma retenção praticamente integral dos frutos do progresso técnico em países desenvolvidos fazendo com que o aumento de produtividade seja absorvida pelos fatores de produção através de uma maior remuneração tanto do trabalho quanto do capital, também ocorre, por outro lado, nos países subdesenvolvidos de economia primário-exportadora, uma transferência do aumento de produtividade para os preços dos produtos primários colocados no mercado internacional, em virtude de uma falta de ordenamento da classe trabalhadora nestes países, que sem uma organização sindical forte não exercem pressão suficiente para a absorção dos frutos do progresso técnico.

Em segundo lugar, em decorrência de características do processo de desenvolvimento econômico, os produtos primários tendem a ter uma elasticidade-renda inferior a dos produtos manufaturados, fazendo com que o consumo de produtos primários tenha uma taxa de expansão inferior a dos produtos manufaturados. Finalmente, alguns anos após estabelecer os fundamentos básicos da tese da deterioração secular dos termos de troca entre produtos primários e produtos manufaturados, Prebisch chamou a atenção para o impacto negativo das políticas comerciais implementadas pelos países desenvolvidos sobre os termos de troca dos países subdesenvolvidos. Assim, ao colocar restrições à entrada de produtos primários nos seus mercados internos e ao 
conceder estímulos a produção domestica de produtos primários, os países desenvolvidos tendem a afetar os preços internacionais através de restrições a demanda e ampliação da oferta internacional de produtos primários.

\section{Dependência e Subdesenvolvimento na América Latina}

A abordagem sobre dependência e subdesenvolvimento na América Latina, neste tópico, esta baseada nas ideias e análises de Celso Furtado, Fernando Henrique Cardoso e Enzo Faletto, com as contribuições de André Gunder Frank e Osvaldo Sunkel.

O ponto central do pensamento de Furtado $(1990 ; 2002)$ é sua análise do subdesenvolvimento ao nível da economia nacional. Segundo a teoria dual-estruturalista, existiriam numa economia subdesenvolvida dois setores básicos: o primeiro é um núcleo onde já penetrou a forma capitalista de produção, denominado de setor avançado; e o segundo, composto de um sistema pré-capitalista que cobre o resto da economia, e chamado de atrasado. Para que o desenvolvimento possa ocorrer, seria necessário, superar uma série de obstáculos estruturais que impedem a absorção do setor atrasado pelo avançado. O subdesenvolvimento é um processo histórico autônomo, e não uma etapa pela qual tenham necessariamente passado as economias que já alcançaram grau superior de desenvolvimento. Isso equivale dizer que o subdesenvolvimento não é uma fase inevitável do processo de formação das economias capitalistas, constituindo, antes, na realidade, uma deformação.

O elemento da dependência, na verdade, desempenha papel central no argumento de Furtado. Os países dependentes serão sempre subdesenvolvidos. A transição do subdesenvolvimento para o desenvolvimento é dificilmente concebível, no quadro da dependência, valendo notar que o avanço do processo de industrialização na periferia faz crescer o controle por grupos estrangeiros do aparato produtivo ai localizado. Em consequência, a dependência, antes imitação de padrões externos de consumo mediante a importação de bens, agora se enraíza no sistema produtivo. A visão do desenvolvimento que prevalece nessas circunstâncias é a de um processo mimético de padrões culturais importados, de uma modernização que significa a adoção de moldes de consumo sem uma verdadeira transformação de fôlego nas estruturas da economia e da sociedade que a adotaram.

Cardoso e Faletto (1970) indicam que a situação de subdesenvolvimento produziu-se historicamente quando a expansão do capitalismo comercial e depois do industrial vinculou a um 
mesmo mercado economias que, além de apresentar graus variados de diferenciação do sistema produtivo, passaram a ocupar posições distintas na estrutura global do sistema capitalista. Dessa forma, entre as economias desenvolvidas e as subdesenvolvidas não existe uma simples diferença de etapa ou de estágio do sistema produtivo, mas também de função ou posição dentro de uma mesma estrutura econômica internacional de produção e distribuição. $O$ conceito de subdesenvolvimento, tal como é usualmente empregado, refere-se mais a estrutura de um tipo de sistema econômico, com predomínio do setor primário, forte concentração da renda, pouca diferenciação do sistema produtivo e, sobretudo, predomínio do mercado externo sobre o interno. De acordo com os autores, isso é insuficiente para explicar o processo.

Deve-se levar em consideração que uma sociedade pode sofrer transformações profundas em seu sistema produtivo sem que se constituam, ao mesmo tempo, de forma plenamente autônoma os centros de decisão e os mecanismos que os condicionam. Não existe um nexo imediato entre a diferenciação do sistema econômico e a formação de centros autônomos de decisão. A esfera política do comportamento social influi necessariamente na forma do processo de desenvolvimento. Por isso, partindo de uma interpretação global do desenvolvimento, os argumentos baseados em puros estímulos e reações do mercado são insuficientes para explicar a industrialização e o progresso econômico (MACHADO, 1999).

Ao considerar a situação de dependência, na análise do desenvolvimento latinoamericano, o que Cardoso e Faletto pretendem ressaltar é que o modo de integração das economias nacionais no mercado internacional supõe formas definidas e distintas de inter-relação dos grupos sociais de cada país, entre si e com os grupos externos. Pois bem, quando se aceita a perspectiva de que os influxos do mercado, por si mesmos, não são suficientes para explicar a mudança nem para garantir sua continuidade ou sua direção, a atuação das forças, grupos e instituições sociais passa a ser decisiva para a análise do desenvolvimento.

Os atores reconsideraram os problemas do desenvolvimento econômico a partir de uma perspectiva de interpretação que insiste na natureza política dos processos de transformação econômica. Também procurou-se mostrar que a referência as situações históricas nas quais se dão as transformações econômicas é essencial para a compreensão do significado dessas transformações, bem como para a análise de seus limites estruturais e das condições que as tornam possíveis. Formulando nesses termos a relação entre processo econômico, condições estruturais e situação histórica, ficam evidentes as limitações de utilização dos esquemas teóricos relativos ao 
desenvolvimento econômico e a formação da sociedade capitalista dos países desenvolvidos para a compreensão da situação dos países latino-americanos. Não só o momento histórico é distinto, como as condições estruturais do desenvolvimento e da sociedade tornaram-se historicamente diversas.

O reconhecimento dessas diferenças levou a crítica dos conceitos de subdesenvolvimento e periferia econômica, e a valorização do conceito de dependência, como instrumento teórico para acentuar tanto os aspectos econômicos do subdesenvolvimento quanto os processos políticos da dominação de uns países por outros, de umas classes sobre outras, num contexto de dependência nacional. Por outro lado, através da crítica do conceito de dependência, Cardoso e Faletto retomaram a tradição no pensamento político de que não existe uma relação metafísica de dependência entre uma Nação e outra, um Estado e outro. Essas relações se tornam possíveis concretamente por intermédio de uma rede de interesses e de coações que ligam uns grupos sociais aos outros, umas classes as outras. Sendo assim, é preciso determinar interpretativamente a forma que essas relações assumem em cada situação básica de dependência, mostrando como Estado, Classe e Produção se relacionam.

Gunder Frank (1980) busca adotar uma explicação do subdesenvolvimento através da análise das relações dependentes de produção e de troca no interior do processo mundial de acumulação de capital. $\mathrm{O}$ autor analisa a dependência por meio das relações internas quando não dos modos de produção, levando em conta sua determinação mútua e vínculos com as relações de troca externas, particularmente, embora não exclusivamente, com a metrópole. Ele examina a dinâmica interna determinante no processo histórico da acumulação ou desacumulação de capital e seus estágios distintos de desenvolvimento ou subdesenvolvimento. Situa todos esses elementos dentro do processo histórico unitário do desenvolvimento do sistema capitalista mundial como um todo. Isso significou enfatizar o processo da acumulação de capital, mas na medida do possível, examinando suas diferentes modalidades nas várias partes do mundo simultaneamente a cada estágio do processo histórico mundial unitário, ao invés de considerar as histórias regionais ou nacionais serialmente, uma pós a outra, cada uma tangencialmente relacionada ao processo como um todo e nem um pouco relacionadas entre si.

A tentativa do autor era transcender a abordagem da dependência, mas ainda sem abandoná-la, nem renunciar ao enfoque no subdesenvolvimento, e de prosseguir na direção da integração da dependência e do subdesenvolvimento no interior do processo mundial de 
acumulação. Através da análise do relacionamento entre as relações de produção e de troca, o autor procurou examinar, por um lado, as contribuições diferenciais de cada uma das principais regiões do mundo ao processo mundial de acumulação de capital durante cada um dos seus principais estágios de desenvolvimento e, por outro lado, analisar as consequências causadoras do subdesenvolvimento dessa participação na acumulação mundial para cada uma das principais regiões do terceiro mundo, hoje subdesenvolvido.

Gunder Frank (1983) enfatiza a dependência subordinada destas áreas, inclusive da América Latina, no interior do desenvolvimento capitalista mundial, enquanto causa do desenvolvimento de seu subdesenvolvimento. A idéia básica do autor, em sua análise econômica da dependência, era de que a industrialização que ocorria na América Latina correspondia tão somente a uma nova modalidade de exploração secular que o imperialismo impunha aos trabalhadores da região subdesenvolvida, em aliança com a elite local. Nesta, o processo de acumulação era indissociável da expansão capitalista internacional e do imperialismo, e constituía parte de um processo que apenas enriquecia os países desenvolvidos e a pequena elite dominante local que os representava. O sistema capitalista mundial funciona na base da formação e exploração de um conjunto de satélites e subsatélites, que se reproduzem dentro de cada país, formando subsistemas de exploração domésticos ligados ao sistema mundial.

Sunkel (1976) defende que um esquema analítico adequado ao estudo do subdesenvolvimento e a formulação de estratégias de desenvolvimento deve repousar nas noções de processo, estrutura e sistema. Não se pode admitir que o subdesenvolvimento seja um momento na evolução de uma sociedade, econômico, político e culturalmente isolado e autônomo. Postulase, ao contrário, que o subdesenvolvimento faz parte do processo histórico global do desenvolvimento, que o subdesenvolvimento e o desenvolvimento são duas faces de um mesmo processo universal, que ambos os processos são historicamente simultâneos, que estão funcionalmente vinculados, isto é, interagem e se condicionam mutualmente, e que sua expressão geográfica materializa-se em duas grandes polarizações: por um lado, a polarização do mundo entre os países industrializados, avançados, desenvolvidos e centrais e os países subdesenvolvidos, atrasados, pobres, periféricos e dependentes; e por outro, uma polarização dentro dos países, em espaços, grupos sociais e atividades avançadas e modernas, e em espaços, grupos e atividades atrasadas, primitivas, marginalizadas e dependentes. 
O argumento central de Sunkel, em sua análise da dependência, partia do postulado de que havia no mundo uma única economia capitalista. Tanto no que se refere a padrões tecnológicos como a padrões de consumo ela era total e crescentemente integrada, especialmente através da expansão mundial das corporações transnacionais. O problema do subdesenvolvimento residia no fato de que, enquanto no centro a maior parte dos trabalhadores encontra-se integrada ao mundo moderno, na periferia isso ocorria somente com uma pequena fração da população. Pior ainda, o avanço desse modelo mundial de acumulação tinha efeitos sociais desagregadores, porque tendia a marginalizar os agentes econômicos com maiores potencialidades produtivas.

O desenvolvimento e o subdesenvolvimento, portanto, podem ser compreendidos como estruturas parciais, mas interdependentes, que configuram um único sistema. Uma característica principal que diferencia essas duas estruturas é que a desenvolvida, sobretudo em virtude de sua capacidade endógena de crescimento é a dominante, e a subdesenvolvida, em parte em função do caráter induzido de sua dinâmica, é dependente. E isso se aplica tanto ao que se observa entre os países quanto ao que se constata entre regiões dentro de um mesmo país.

Toda essa discussão e debate, envolvendo o processo de dependência e subdesenvolvimento na América Latina, demarca a importância do tema para o entendimento dos caminhos do desenvolvimento econômico e social do continente latino-americano.

\section{A dialética da dependência na América Latina}

Nos anos da década de 1960 passou-se a estudar as especificidades do desenvolvimento econômico no período do pós-segunda guerra mundial e as relações políticas na América Latina, sobretudo o comportamento social e político das burguesias do continente. As reflexões de Ruy Mauro Marini apontaram as especificidades das burguesias, as questões da superexploração da força de trabalho e do subimperialismo. Marini foi um dos teóricos da teoria da dependência e crítico das concepções defendidas na Comissão Econômica para a América Latina (Cepal). Fernando Henrique Cardoso, em conjunto com Enzo Faletto, desenvolveu a teoria da interdependência e do desenvolvimento associado dos países periféricos aliados aos países centrais. Cardoso defende que a partir dos anos finais da década de 1950 ocorreu uma nova situação de dependência que superou a fase imperialista do capitalismo, o que permitiu, dessa forma, o desenvolvimento associado da periferia. Neste tópico, vamos analisar o embate entre essas duas correntes sobre a teoria da dependência. 
Marini (2017), em seu texto "Dialética da Dependência", defendeu que a expressão dependência significa a relação de subordinação entre países formalmente independentes, e que essa relação foi posta pelos Europeus na América Latina desde o período colonial, com o desenvolvimento do capitalismo comercial. Marini entende a noção de dependência como subordinação. Neste primeiro ponto, podemos verificar as diferenças acerca da noção de dependência de Cardoso (1970), uma vez que esse último advoga que a vinculação das economias periféricas ao mercado internacional se dá pelo estabelecimento de laços entre o centro e a periferia que não se limita apenas, como antes, ao sistema de importações-exportações, agora as ligações se dão também através de investimentos industriais diretos feitos pelas economias nos novos mercados nacionais. A especificidade da situação de dependência está em que os interesses externos radicam cada vez mais no setor de produção para o mercado interno e, consequentemente, se alicerçam em alianças políticas que encontram apoio nas populações urbanas. Por outro lado, a formação de uma economia industrial na periferia do sistema capitalista internacional minimiza os efeitos da exploração tipicamente colonialista em busca de solidariedade não só nas classes dominantes, mas no conjunto dos grupos sociais ligados a produção capitalista moderna: assalariados, técnicos, empresários, burocratas etc.

De acordo com Cardoso, a nova fase da dependência permitiria superar a subordinação, expressando assim, a sua proposta de possibilidades de desenvolvimento inserido numa relação de dependência, pois nas economias industriais periféricas no período posterior a década de 1950, percebe-se o interesse de industrialização do mercado interno desses países por parte dos países centrais, advindo daí, a possibilidade do desenvolvimento. O autor problematiza a noção de dependência, pois apesar das transformações assinaladas, seria possível manter a ideia de dependência ou, ao contrário, dever-se-ia substituí-la pela interdependência. A existência de um mercado aberto, a impossibilidade da conquista dos mercados dos países mais desenvolvidos pelas economias dependentes e a incorporação contínua de novas unidades de capital externo sob a forma de tecnologia altamente desenvolvida e criada mais em função das necessidades intrínsecas das economias maduras do que das relativamente atrasadas fornecem o quadro estrutural básico das condições econômicas da dependência.

Sendo assim, Cardoso defendeu a teoria da interdependência e do desenvolvimento associado ao capital internacional. A interdependência teria surgido após a década de 1950, momento em que as nações industriais periféricas teriam condições de romper com o atraso através 
de alianças com os países centrais, integrando a América Latina na própria evolução do capitalismo. Dessa forma, observamos a primeira grande diferença entre os autores. Para Marini, o conceito de dependência está inserido na subordinação, já para Cardoso, põe-se a questão da interdependência e o desenvolvimento associado como possibilidade de constituição do capitalismo periférico.

O tema que se seguiu a essa discussão foi a questão da superexploração da força de trabalho. Marini entendeu que nas relações entre os países imperialistas e os países dependentes verificou-se o intercâmbio desigual, uma vez que na América Latina permanece uma produção com baixo padrão tecnológico. Dessa forma, o recurso das burguesias dos países dependentes para compensar as perdas no mercado mundial foi a superexploração do trabalhador, que segundo Marini se caracteriza por três mecanismos: a intensificação do trabalho, a prolongação da jornada de trabalho e a expropriação de parte do trabalho necessário ao operário para repor sua força de trabalho, revelando a especificidade do capitalismo que se fundamente na maior exploração do trabalhador, e não no desenvolvimento de sua capacidade produtiva. $\mathrm{O}$ aumento da intensidade do trabalho aparece como um aumento da mais-valia, obtido através da maior exploração da força de trabalho e não do incremento de sua capacidade produtiva.

De acordo com a visão de Marini, o capitalismo assentado na superexploração do trabalhador deveu-se ao fato de que nos países dependentes a circulação se separa da produção e se efetua basicamente no âmbito do mercado externo, o consumo individual do trabalhador não interfere na realização do produto, ainda que determine a taxa de mais-valia. Para ele, nos países da América Latina que formaram indústrias, o processo de industrialização deu-se diferente dos países imperialistas. Nos países europeus a formação do capitalismo contou com o mercado interno, isto é, incorporou a força de trabalho para sua expansão econômica. No entanto, na América Latina a industrialização não dependeu do dinamismo de uma produção interna, da capacidade de consumo interno. A exportação foi o fator primordial da indústria pautada na produção de bens de consumo suntuosos, de modo que se desconsiderou o consumo popular interno. Marini apontou essa especificidade da América Latina, entendendo que a separação da produção e da circulação produziu uma economia dependente embasada na superexploração do trabalho e da compressão salarial.

Para Cardoso, a industrialização do mercado interno foi responsável pela nova situação de dependência, ou interdependência, portanto, discordando da análise de Marini. Para ele a 
formação da mais-valia relativa na Europa não dependeu da produção latino-americana, a exploração da força de trabalho na América Latina contou com uma combinação de formas, negando assim a superexploração do trabalhador como a base do capitalismo dependente. No entanto, Cardoso não nega que a despeito do avanço do capitalismo moderno, a miséria persistiu, mas entende que esse processo na se relaciona com a superexploração do trabalho, uma vez que a estrutura pré-moderna permaneceu.

Na visão de Cardoso, Marini cometeu o erro de não perceber as oportunidades e o desenvolvimento nos países periféricos. Sendo assim, vinculou a interpretação de Marini a grupos foguistas e guerrilheiros dos anos 1960/70, que não vislumbravam possibilidades de desenvolvimento das nações latino-americanas nos marcos do sistema capitalista, portanto, propunham a luta armada. Daí a caracterização de Marini como o intelectual que fundamenta o estagnacionismo das economias latino-americanas e defende a luta armada.

A polêmica continuou com a publicação do texto "As desventuras da dialética da dependência", de Fernando Henrique Cardoso e José Serra (1978). Nesse texto, os autores propalaram que a política de compressão salarial, no Brasil, veio devido ao reacionarismo das forças militares do pós 1964 e da fraqueza dos sindicatos. Defenderam que em pleno auge mantevese uma política oficial de forte restrição salarial, ficando as melhorias eventualmente obtidas nesse terreno sujeitas as forças de mercado, e não por conta seja da política governamental, seja da ação sindical ou do protesto social, que seguiram tão ou mais reprimidos e inexistentes que antes. $\mathrm{Na}$ expressão do universo teórico e político de Cardoso, com o avanço do desenvolvimento associado a partir das alianças com as empresas modernas internacionais na absorção de tecnologias, se promoveria a produção de mais-valia relativa. As forças de mercado, de acordo com o autor, promoveriam as melhorias salariais. Contudo, nas economias industriais dependentes, em condições de democracia política e alto padrão tecnológico, prover-se-ia melhores condições para os trabalhadores, superando assim, a miséria e o atraso tradicional. Portanto, Cardoso propalou o fim do autoritarismo burocrático dos militares e defendeu o modelo econômico de desenvolvimento associado.

O texto de Cardoso e Serra contra Marini foi produzido no contexto da luta pela Anistia política no Brasil. O escrito foi divulgado primeiramente no México e depois no Brasil, na revista Cebrap, criada por Cardoso. No entanto, a resposta de Marini não teve a mesma divulgação no país, o que fez com que sua obra ficasse marcada, sobretudo no Brasil, pela interpretação dos 
intelectuais opositores. Cardoso e Serra nomearam a produção intelectual de Marini como sendo estagnacionista, isto é, Marini não teria percebido a mudança vivenciada na periferia, o desenvolvimento associado. Cardoso registrou que esse tipo de análise ajudou a racionalizar os argumentos utilizados por parte da esquerda latino-americana, ao longo dos anos sessenta e começo dos setenta, para justificar a luta armada, aceitando a ideia de estagnação.

A polêmica entre os dois autores pode ser facilmente identificada nas duas interpretações, produzidas por Cardoso, sobre o desenvolvimento capitalista latino-americano. Para ele, existem os que creem que o capitalismo dependente baseia-se na superexploração da força de trabalho, é incapaz de ampliar o mercado interno, gera incessante desemprego e marginalidade, e apresenta tendências a estagnação e uma espécie de constante reprodução do subdesenvolvimento, sendo esse o caso das ideias de Marini. Por outro lado, onde ele estava incluído, existem os que pensam que, pelo menos em alguns países da periferia, a penetração do capital industrial-financeiro acelera a produção da mais-valia relativa, intensifica a forças produtivas e, se gera desemprego nas fases de concentração econômica, absorve mão-de-obra nos ciclos expansivos, produzindo, neste aspecto, um efeito similar ao do capitalismo nas economias avançadas, onde coexistem desemprego e absorção, riqueza e miséria.

As obras dos dois autores expressam conclusões teóricas, ideológicas e políticas distintas. Contudo, recuperar suas posições torna-se fundamental para a compreensão da chamada teoria da dependência e do processo social na América Latina. A amplitude dessa discussão e o debate provocado demarcam a importância do tema para o entendimento dos caminhos do desenvolvimento econômico e social do continente latino-americano.

\section{Considerações finais}

A Cepal sempre se preocupou em elaborar uma teoria do desenvolvimento. Em sua análise, a notória insuficiência dinâmica do desenvolvimento latino-americano resultava de duas ordens de causa: de um lado, as estruturas sociais predominantes, que estimulavam o consumo exagerado dos grupos de altas rendas, enfraquecendo o processo de acumulação de capital, isso pressupondo já a necessidade de reformas estruturais; de outro, a deterioração das relações de troca entre centro e periferia, na medida em que a relação de preços entre produtos industrializados e primários evolui de forma totalmente desfavorável para estes últimos. Nesse ponto, contestam-se os conceitos fundamentais da teoria tradicional do comércio exterior (a divisão internacional do trabalho, 
baseada nas vantagens comparativas), observando-se que a organização social e da força de trabalho, nos centros industrializados, permitiram que os ganhos de produtividade, obtidos com o desenvolvimento tecnológico, não fossem transferidos para a periferia na forma de redução de preços. Além disso, os produtos primários representavam uma porcentagem decrescente na demanda global, e o desenvolvimento da técnica permitiu a sua substituição e redução de participação no valor dos bens finais; e, finalmente, o protecionismo dos países industrializados estreita o acesso aos seus mercados.

Toda essa construção teórica sobre a América Latina, consubstanciada por recomendações de políticas econômicas e missões de assistência técnica aos países latino-americanos, fizeram da Cepal uma das principais fontes mundiais de informações e análise sobre a realidade econômica e social da região. Trata-se de um corpo analítico específico, aplicável a condições históricas próprias da periferia latino-americana.

A visão do subdesenvolvimento como um processo histórico autônomo indica que os países não precisam passar por essa etapa, ou mesmo permanecer nela. Então o subdesenvolvimento não é uma exigência para se chegar a uma economia capitalista. No entanto, dependência e subdesenvolvimento estão diretamente conectados, ser subdesenvolvimento é ser dependente. Outra possibilidade é reconhecer a dependência como uma relação entre os países, seja na área econômica, política ou social. Não existe a visão de subdesenvolvimento enquanto estrutura inferior, mas como uma posição dentro das relações entre os mesmos. Os sistemas produtivos são distintos, assim como os graus de vinculação entre os sistemas econômicos, cada um cumpre seu papel.

Entre dependência e interdependência, desenvolvimento e subdesenvolvimento, a amplitude dessa discussão e o debate provocado demarcam a importância do tema para o entendimento dos caminhos do desenvolvimento econômico e social do continente latinoamericano. Esperamos com esse texto contribuir com essa análise.

\section{Referências}

BARBOSA, Wilson do Nascimento. Relembrando a formação da CEPAL. Pesquisa \& Debate. Revista do Programa de Estudos Pós-Graduados em Economia Política, [S.1.], v. 15, n. 2(26), out. 2012. ISSN 1806-9029. Disponível em: 〈https://revistas.pucsp.br/rpe/article/view/11937〉. Acesso em: 31 jul. 2020. 
BIELSCHOWSKY, Ricardo. Cinquenta anos de pensamento na Cepal - uma resenha. In: BIELSCHOWSKY, Ricardo (Org.). Cinquenta anos de pensamento na Cepal. Rio de Janeiro: Record, 2000. p. 13-68.

CARDOSO, Fernando Henrique; FALETTO, Enzo. Dependência e Desenvolvimento na América Latina. Rio de Janeiro: Zahar,1970.

FRANK, André Gunder. Acumulação dependente e subdesenvolvimento: repensando a teoria da dependência. São Paulo: Brasiliense, 1980.

FRANK, André Gunder. Reflexões sobre a crise econômica mundial. Zahar editores, 1983.

FURTADO, Celso. Entre inconformismo e reformismo. Estudos Avançados, São Paulo, v. 4, n. 8, p. 166-187, abr. 1990. Disponível em:

$<$ http://www.scielo.br/scielo.php?script=sci_arttext\&pid=S010340141990000100013\&lng=en\&n $\underline{\mathrm{rm}=\mathrm{iso}}>$. Acesso: 31 jul. 2020.

FURTADO, Celso. Em busca de novo modelo. São Paulo: Paz e Terra, 2002.

GURRIERI, Adolfo. La economia politica de Raúl Prebisch. E/CEPAL/IN. 16. 1981. Disponível em: 〈https://repositorio.cepal.org/handle/11362/33090>. Acesso em: 5 jan. 2021.

KANNEBLEY JÚNIOR, Sérgio; GREMAUD, Amaury Patrick; RENNÓ, Ricardo de Almeida. A tendência secular dos termos de troca brasileiros revisitada: 1850 - 2000. In: Anais.. Niterói: ANPEC, 2001.

MACHADO, Luiz Toledo. A teoria da dependência na América Latina. Estudos Avançados, São Paulo, v. 13, n. 35, p. 199-215, abr. 1999. Disponível em:

$<$ http://www.scielo.br/scielo.php?script=sci_arttext\&pid=S010340141999000100018\&lng=en\&n $\underline{\mathrm{rm}=\mathrm{iso}}>$. Acesso: 31 jul. 2020.

MARÇAL, Emerson Fernandes. Há Realmente uma Tendência a Deterioração dos Termos de Troca? Uma Análise dos Dados Brasileiros. EconomiA, Brasília (DF), v. 7, n. 2, p. 307-329, mai.-ago. 2006.

MARINI, Ruy Mauro. Dialética da dependência. Germinal: Marxismo e Educação em Debate, Salvador, v. 9, n. 3, p. 325-356, dez. 2017.

PREBISCH, Raúl. O desenvolvimento econômico da América Latina e seus principais problemas. Revista Brasileira de Economia, Rio de Janeiro, v. 3, n. 3, p. 47-111, 1949.

SERRA, José; CARDOSO, Fernando Henrique. As desventuras da dialética da dependência. Estudos CEBRAP, São Paulo, n. 23, p. 34-80, 1978.

SUNKEL, Osvaldo; PAZ, Pedro. A teoria do desenvolvimento econômico. São Paulo: Difel, 1976. 
VIEIRA, Rosa Maria; CARVALHO, Carlos Eduardo. Dossiê: desenvolvimentismo e pensamento estruturalista. Pesquisa \& Debate, São Paulo, v. 15, n. 2(26), p. 5-12, 2004.

Recebido: 18/07/2021

Aceito: 18/07/2021

Publicado: 01/09/2021

* Doutor em História Social pela FFLCH/USP. Lattes: http://lattes.cnpq.br/9483626257822978. Orcid: https://orcid.org/0000-0003-2764-9312. 